\title{
CROMOMICOSE CEREBRAL
}

\author{
REGISTRO DE UM CASO
}

\author{
LUCIANO DE BOUZA QUEIROZ * ANAMARLI NUCCI ** \\ FLAVIO B. LOPES DE FARIA *** ROGERIO DE JESUS PEDRO **** \\ NUBOR O. FACURE *****
}

Os fungos de cor pardacenta, pigmentados ou dematiáceos, distribuidos pelos gêneros Phialophora, Fonsecaea e Cladosporium ${ }^{2,10}$ causam no homem dois tipos distintos e aparentemente independentes de doenças ${ }^{9}$.

A cromomicose cutânea é freqüente e predomina nos paises tropicais. Caracteriza-se por extensas lesões verrucosas, de evolução crônica, envolvendo principalmente os membros inferiores. Diversas espécies de Phialophora e o Cladosporium carrionii têm sdo implicadas como agentes etiológicos ${ }^{2,6}$.

A cromomicose cerebral, por outro lado, é rara, constando na literatura mundial apenas cerca de 40 casos. Ocorre tanto em clima tórrido como temperado. Em quase todos os casos em que se obtiveram culturas do fungo, foi possível definir a espécie como Cladosporium trichoides $2, \mathbf{4 , 5 . 1 0}$. Os pacientes, em geral, não apresentavam doença cutânea conconitante, e a via de acesso dc agente ao encéfalo permanece obscura ${ }^{9}$.

No Brasil, Spina-França, Britto e Almeida 8 em 1953, publicaram um caso anátomo-clínico de cromomicose do sistema nervoso central. Julgamos assim, de interesse, registrar mais um caso desta rara neuromicose.

\section{OBSERVAÇO}

S.A.N., 59 anos, sexo masculino, branco, operador de máquinas, internado no Hospital de Clínicas da UNICAMP em 17-5-1978. Sua história clínica teve início em outubro de 1977, quando notou cefaléia difusa, de média intensidade. A cefaléia, associou-se parestesia do braço e perna esquertas, instaladas de forma lenta e progressiva. $O$ paciente continuou trabalhando até fins de novembro, quando por insistência dos familiares, procurou tratamento. Apresentava desvio da rima bucal para a direita e dificuldade motora do braço e perna esquerdos. Não referia perda de consciência, fenômenos convulsivos ou vômitos nesta época. Recebeu como orientaçăo

Trabalho da Faculdade de Ciências Médicas da Universidade Estadual de Campinas (UNICAMP), Departamento de Anatomia Patológica (Chefe - Prof. J. Lopes de Faria): * Professor Assistente *** Residente; Departamento de Neurologia Clínica e Cirúrgica: **** Coordenador do Departamento; ** Professor Assistente; Disciplina de Moléstias Transmissiveis do Departamento de Clínica Médica: *** Prof. Assistente. 
médica o uso de droga antihipertensiva e afastamento do trabalho. Nos dias subseqúentes acentuou-se o déficit motor, e a cefaléia tornou-se diária e rebelde aos analgésicos comuns. Advieram crises de alucinaçăo visual e agitação psicomotora. O paciente foi internado por duas ocasióes em outros hospitais, sem obter melhora. A partir de fevereiro de 1978, tornou-se inativo, inapetente, emagrecendo e apresentando frequentes episódios de vômitos. A cefaléia era constante e intensa. Segundo seus familiares, o paciente aparentava ter déficit visual e possivelmente auditivo, e já năo os reconhecia. Antecedentes pessaais - Natural e procedende da região de Campinas. Ausência de dados epidemiológicos dignos de nota. Alcoólatra e tabagista há 35 anos. Exame fisico - Paciente em mau estado geral, desnutrido e desidratado. Pressão arterial 140/110 mm Hg.; pulso 80 bat./min. Temperatura de 38,50C. Pulmźes com estertores crepitantes nas bases e roncos disseminados. Escaras de decúbito na regiăo sacral e cotovelos. Hemiplegia espástica completa, proporcionada à esquerda e sinais da série meningorradicular presentes. Exames complementares - Hemograma: hemoglobina $13 \mathrm{~g} / 100 \mathrm{ml}$; hematócrito $39 \%$; valor globular 0,96 ; leucócitos 13.400 por mms (4-85-0-0-4-7); plaquetas normais; granulações tóxicas nos neutrófilos. Sódio $140 \mathrm{mEq} / 1$. Potássio $4,2 \mathrm{mEq} / 1$. Uréia $50 \mathrm{mg} / 100 \mathrm{ml}$. Creatinina $1,75 \mathrm{mg} / 100 \mathrm{ml}$. Os exames de líquido cefalorraqueano são resumidos na tabela 1 . Radiografia de tórax: normal. Eletrencefalograma (1-6-78) evidenciou sinais de comprometimento da atividade elétrica cerebral, principalmente no hemisfério esquerdo, áreas temporais. Evoluço - O tratamento consistiu de antibioticoterapia com ampicilina, correção dos distúrbios hidroeletroliticos e terapia de suporte. Apesar destas medidas, o caso evoluiu para o coma e o paciente passou a apresentar papilas de contornos imprecisos, sendo proposta uma angiografia cerebral. o precário estado clínico-neurológico, com grave insuficiencia ventilatória, impediu um estudo angiográfico completo, porém uma carotidoangiografia esquerda resultou normal. O paciente faleceu em 6-6-78. Os diagnósticos clínicos foram os de hipertensăo intracraniana por provável abcesso cerebral e meningite de etiologia não esclarecida.

Necrópsia (A. 125/78). Foi restrita à cabeça. Observaram-se escaras de decúbito na regiăo sacral e nos cotovelos, sem outras lesర̃es cutaneas. O encéfalo, pesando $1.550 \mathrm{~g}$ após fixação em formol, mostrava intenso edema difuso, forte hiperemia generalizada da leptomeninge, hérnia de uncus bilateral e intensa aterosclerose dos vasos da base. Os cortes frontais dos hemisférios cerebrais revelaram nos núcleos basais à direita, um abcesso encapsulado medindo cerca de $1,5 \mathrm{~cm}$ de diametro, cujo conteúdo era pastoso e esverdeado. Em um corte pelo quiasma optico, o abcesso destruia o putamem, cápsula externa, claustrum e cápsula interna, atingindo o ventrículo lateral (Fig. 1). Os ventrículos apresentavam volume normal e não havia desvio da linha média. O romboencéfalo mostrava intenso edema difuso. Exame microscopico - $\mathrm{O}$ abcesso é constitufdo por extensa área de necrose, bem delimitada por tecido fibroso denso. Nesta cápsula, chamam a atenção numerosos fungos arredondados, de cor castanha, nitidamente visíveis já na coloração pela hematoxilina-eosina, e medindo 10 a $12 \mu$ de diametro (Fig. 2). A técnica do PAS, bem como a impregnação argêntica segundo Grocott revelam, além de fungos arredondados, grande número de hifas septadas com diametro de 2 a $3 \mu$, localizadas, preferencialmente, no material necrótico (Fig. 3). Tais hifas têm, na coloração pela hematoxilina-eosina, leve tonalidade castanha. As formas arredondadas (clamidosporos) dão origem a hifas por brotamento, mas com 


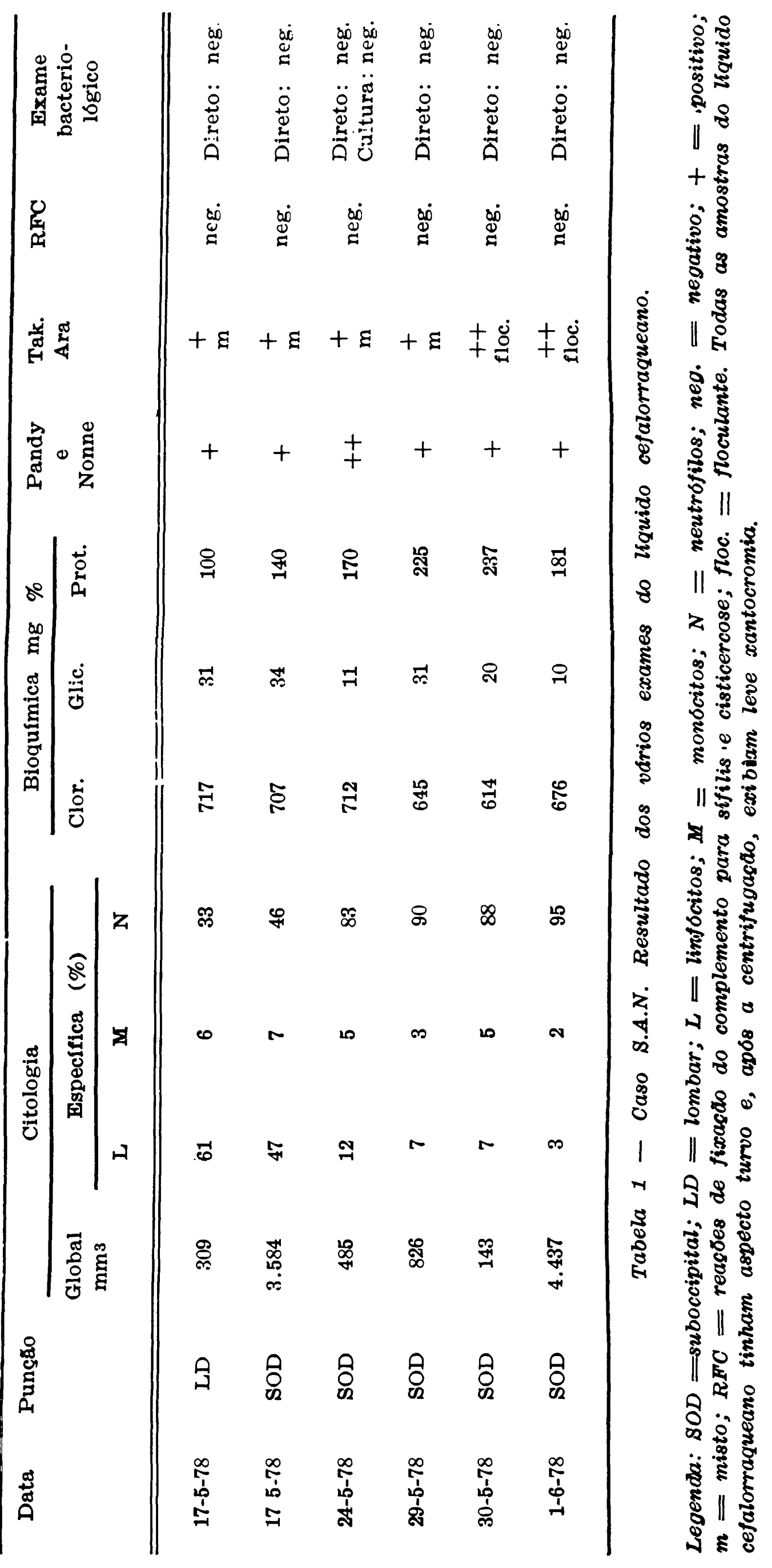




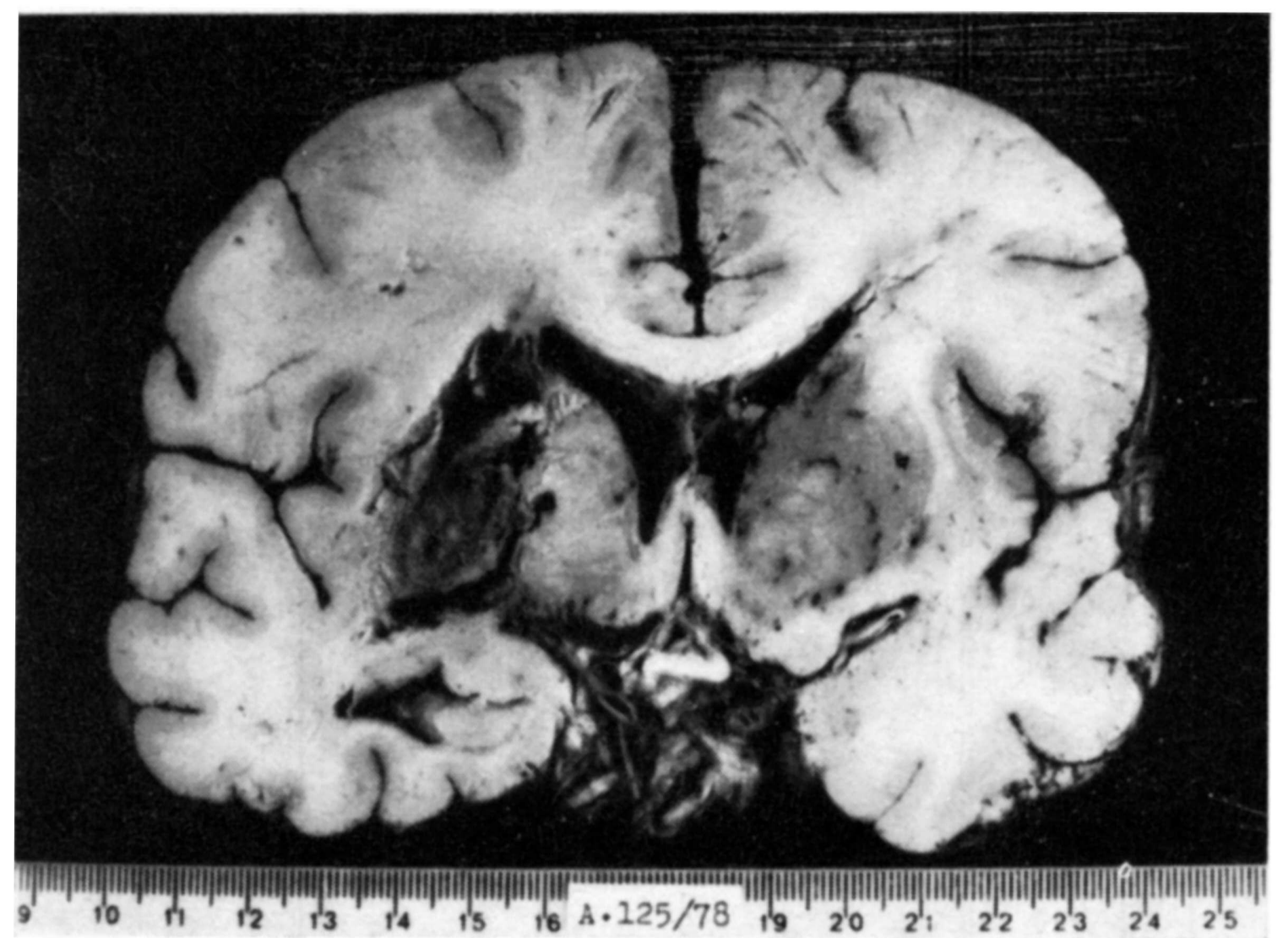

F'ig. 1 - Caso 8.A.N. Area de nacrose nos núcleos da base d direita, atingindo o ventriculo lateral.

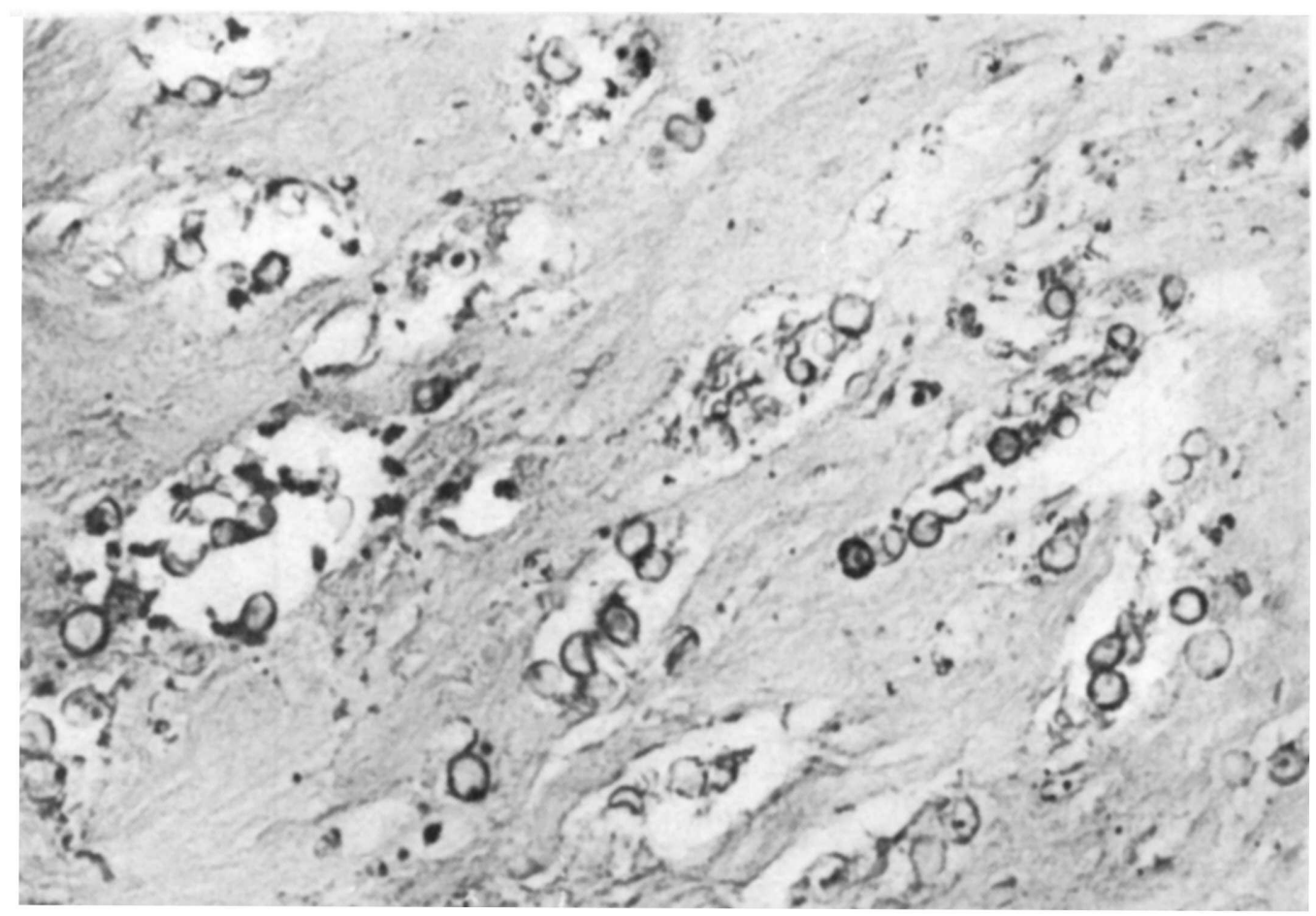

IFig. 2 - Caso S.A.N. Cópsula do abcesso. Numerosos fungos arredondados de cor marrom ( $B$ E. $390 \mathrm{X}$ ). 


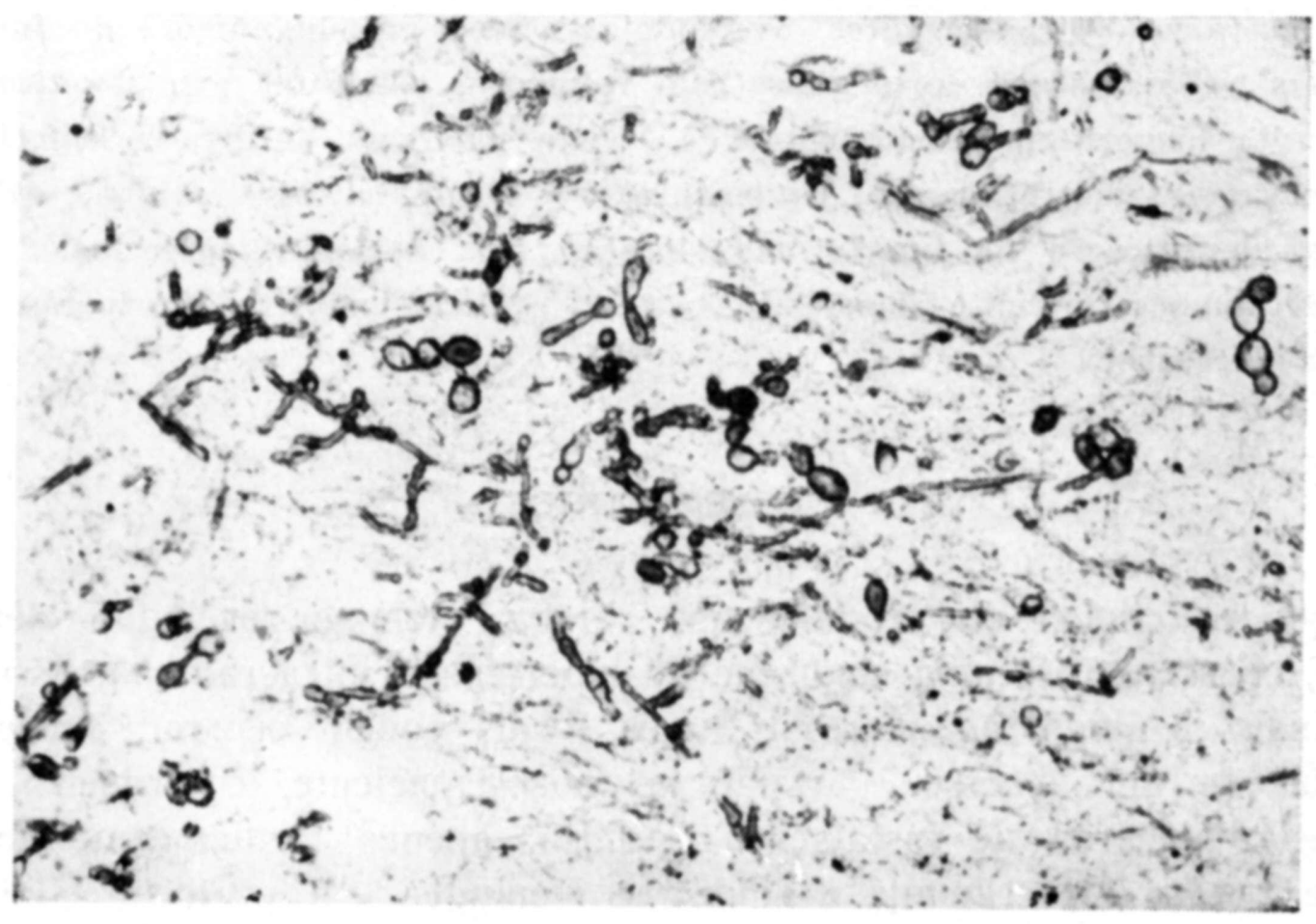

Fig. 3-Caso S.A.N. Material necrótico do interior do abcesso. Fungos de forma arredondada $e$ hifas septadas (PAS $330 \mathrm{X}$ ).

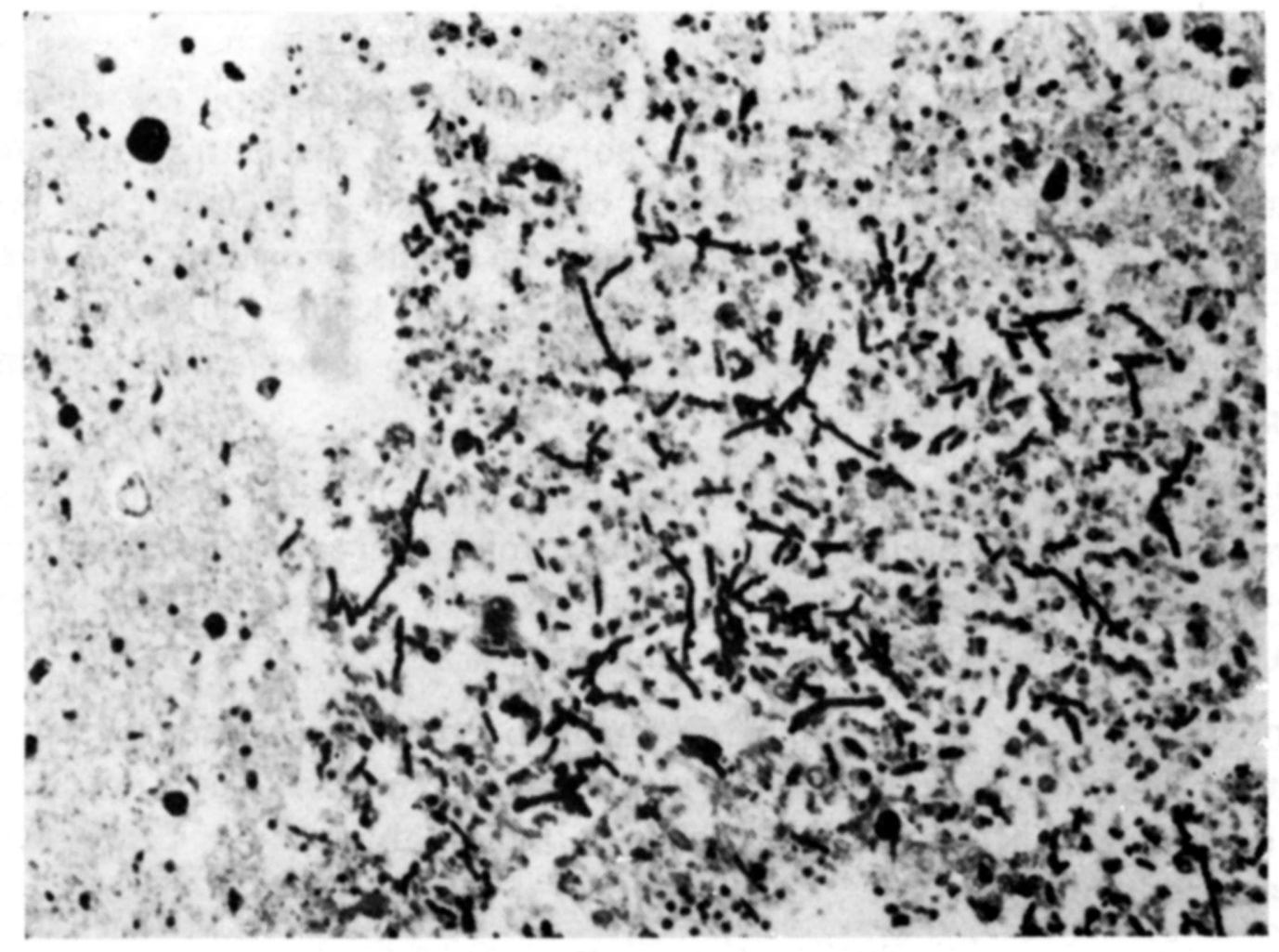

Fig. 4-Caso S.A.N. Leptomeninge da medula oblonga. Abundantes fungos em forma hifa em meio a exsudato. Tecido nervoso a esquerda, com numerosos corpos amiláceos (Grocott $200 \mathrm{X}$ ). 
frequência encontram-se muitas hifas sem clamidósporos. $\mathrm{Na}$ periferia do abcesso principal há vários outros menores, contendo, também, grande número de fungos. Na margem das lesões, nota-se forte gliose com volumosos astrócitos gemistocíticos. Observa-se discreta hemorragia subaracnóidea e leve a moderado infiltrado linfocitário com alguns leucócitos neutrófilos na leptomeninge. Nesta, a nivel bulbar (Fig. 4), \& possivel a identificação de fungos na coloração pela hematoxilina-eosina. A técnica de Grocott também permite demonstrá-los em pequeno número na leptomoninge do hipocampo e cerebelo.

\section{COMENTARIOS}

O quadro clínico da cromomicose cerebral tem-se revelado relativamente uniforme, constando de uma síndrome de hipertensão intracraniana, associada ou não a sinais meningorradiculares. Sinais focais podem ocorrer, expressando a localização de um abcesso. Assim, no nosso paciente, o primeiro sinal foi hemiparesia esquerda de instalação insidiosa, apenas tardiameente enriquecida pela hipertensão intracraniana e síndrome meníngea. A evolução clínica indica uma lenta expansão do abcesso nos núcleos da base à direita que, após comprometer a cápsula interna, atingiu o ventrículo lateral, permitindo o acesso do agente etiológico ao líquido cefalorraqueano. Daí desenvolveu-se a meningite, principalmente na base do encéfalo, onde o número de parasitas era maior.

Em concordância com a literatura, não foram encontradas lesões cutâneas atribuíveis à micose. Porêm, tendo sido a necrópsia parcial, tornou-se impossível investigar outras eventuais portas de entrada como os pulmões 2 e os seios paranasais ${ }^{1}$.

Não consta que o paciente tivesse doença consuntiva ou estivesse sob terapêutica imunossupressora. Este fato torna improvável a hipótese de a infecção fúngica ser oportunista, contrariamente ao observado em outras neuromicoses ? $\mathrm{Na}$ literatura, os casos de cromomicose cerebral não têm mostrado associação com depressão do sistema imunitário, exceto em raras ocasiões 9 . A inespecificidade do quadro clínico, bem como a ausência de lesões cutâneas, dificulta o diagnóstico etiológico em vida, sendo o caso rotulado genericamente como abcesso cerebral 4,9 .

O líquido cefalorraqueano pode mostrar hipercitose à custa de leucócitos neutrófilos e/ou hiperproteinorraquia, como foi observado em nosso caso. $O$ agente etiológico não parece ter sido demonstrado ao exame direto do LCR 4.5 e foi recuperado em cultura apenas uma vez ${ }^{4}$.

A oportunidade de se efetuar o diagnóstico etiológico aumenta com a cultura do material do abcesso obtido cirurgicamente, como no caso de Brown ${ }^{1}$. As culturas deverão ser praticadas em meios de ágar-Sabouraud e Czapeck, mantidas à temperatura ambiente ${ }^{*}$.

Apesar dos agentes antifúngicos hoje disponíveis, entre eles a 5-fluorcitosina, a mortalidade é alta na cromomicose cerebral ${ }^{3,5}$, tendo evoluido fatalmente 25 dos 31 casos revistos por Duque 4. 
A necrópsia, constitui achado comum, abcesso cerebral delimitado por espessa cápsula fibrosa, onde se observam numerosos fungos caracterizados por sua cor pardacenta. Os aspectos anátomo-patológicos do presente caso em nada diferem de outras descrições ${ }^{4,5,9}$. As revisões de Fetter ${ }^{5}$ e Duque ${ }^{4}$ acentuam a impossibilidade de diagnosticarmos o gênero dos fungos dematiáceos pelo simples exame histológico, sendo, para tal propósito, indispensável a cultura ${ }^{3}$.

RESUMO

As lesões cerebrais por fungos pigmentados são excepcionais. Os autores apresentam um caso de cromomicose do sistema nervoso central, em paciente de 59 anos. $O$ quađro clínico iniciou-se por cefaléias e hemiparesia esquerda, seguida por meningite e síndrome de hipertensão intracraniana, totalizando uma evolução de nove meses. A necrópsia revelou abcesso encapsulado nos núcleos basais à direita e leptomeningite crônica de predomínio na base do encéfalo. $\mathrm{Em}$ ambas as localizações foram demonstrados numerosos fungos de cor castanha, em forma arredondada ou em hifas septadas. Discutem-se as dificuldades diagnósticas desta neuromicose.

\section{SUMMARY}

\section{Cerebral cromomycosis: a case report.}

A case of brain abscess and meningitis due to pigmented fungi is reported. The patient was a 59-year-old white male, who had enjoyed excellent health until October 1977, when he developed headache, later accompanied by paresthesias and weakness in the left-sided extremities. These symptoms worsened progressively and in November of that year he had to quit his job. From February 1978 on he became inactive and anorexic. Intense continuous headache was associated with frequent episodes of vomiting. He gradually became torporous, and according to his relatives, suffered from visual and possibly auditory deficiency. On examination, he was malnourished and dehydrated, with decubitus ulcers. Temperature was $38,5^{\circ} \mathrm{C}$. A left-sided spastic hemiplegia and prominent meningorradicular signs were noted. The CSF was examined six times between May 17th and June 1st and showed variable hypercytosis (143 to 4,437 leucocytes/ $\mathrm{cu} \mathrm{mm}$ ) with predominance of neutrophils (up tp 95\%), low glucose and high protein concentrations. No microorganisms were identified. Electroencephalographic study disclosed a low background activity especially in left temporal areas. Despite supportive care and antibiotic therapy he lapsed into coma. Carotid angiography was normal on June 1st. He remained in deep coma until his death on June 6th, 1978.

Necropsy was limited to the brain, which weighed $1,550 \mathrm{~g}$ after fixation and showed diffuse intense edema and hyperemia. On coronal sectioning an encapsulated abscess was found in the right basal ganglia, which also involved the internal capsule, and measured $1.5 \mathrm{~cm}$ in diameter. Microscopical examina- 
tion disclosed large numbers of brownish fungi, appearing both as oval yeasts and as septate hyphae in the thick fibrous capsule and in the necrotic content of the abscess. The same organisms were demonstrated in moderate numbers in the leptomeninges of the medulla oblongata and, less frequently, of the hippocampal region and cerebellum.

\section{REFHRENCIAS}

1. BROWN, J. W.; NADELL, J.; SAUDERS, C. V. \& SARDEGA, L. - Brain abcess caused by Cladosporium trichoides (Bantianum): a case with paranasal sinus involment. South. Med. J. (Birmigham) 69:1519, 1976.

2. CARRIóN, A. L. - Chromoblastomycosis and related infections: new concepts, differential diagnosis and nomenclatorial implications, Int. J. Dermatol. (Philadelphia) 14:27, 1975.

3. COLLOMB, H.; DUMAS, M.; GIRARD, P. L. \& N'DIAYE, I. P. - Dématiomycose cérébrale (Cladosporiose cérébrale). Un cas chez un noir sénégalais. Sem. Hop. Paris 49:2857, 1973.

4. DUQUE, O. - Cladosporiosis of the Central Nervous Tissue. In Handbuch der Speziellen Pathologischen Anatomie und Histologle III/5, Springer-Verlag, Berlin, pp. 700-718, 1971.

5. FETTER, B. F.; KLINTWORTH, G. K. \& HENDRY, W. S. - Mycoses of the Central Nervous System. Williams \& Wilkins, Baltimore, pp. 63-73, 1967.

6. LACAZ, C. da S. - Micologia Médica. Sarvier, São Paulo, pp. 295-310, 1973.

7. QUEIROZ, L. S.; NUCCI, A. \& FARIA, J. L. - Candidíase sistêmica com localizaçăo encefálica: estudo anátomo-clínico de cinco casos. Arq. Neuro-Psiquiat. (São Paulo) 34:18, 1976.

8. SPINA-FRANCA, A.; BRITTO, T. \& ALMEIDA, F. P. - Cromomicose do sistema nervoso: estudo anátomo-clínico de um caso. Arq. Neuro-Psiquiat. (Săo Paulo) $11: 265,1953$.

9. SYMMERS, W. St. C. - A case of cerebral chromoblastomycosis (Cladosporiosis) occurring in Britain as a complication of polyarteritis treated with cortisone. Brain $83: 37,1960$.

10. Vollum, D. I. - Chromomycosis: a review. Br. J. Dermatol. (London) $96: 454$. 1977.

Departamento de Anatomia Patologica - Fraculdade de Ciencias Medicas da Universidade Estadual de Campinias (UNICAMP) - Caixa Postal 117a 18100 Campinas, SP - Brasil. 